\title{
Anti-oxidant activity of avicularin and isovitexin from Lespedeza cuneata
}

\author{
Ju Sung Lee ${ }^{1}$ Ah Young Lee ${ }^{2}$ Norman G. Quilantang ${ }^{1}$. \\ Paul John L. Geraldino ${ }^{3} \cdot$ Eun Ju Cho ${ }^{4}$ Sanghyun Lee ${ }^{1}$
}

Received: 4 March 2019 / Accepted: 9 April 2019 / Published Online: 30 June 2019

(C) The Korean Society for Applied Biological Chemistry 2019

\begin{abstract}
This study evaluated the anti-oxidant activity of avicularin and isovitexin from Lespedeza cuneata using 2,2-diphenyl-1picrylhydrazyl (DPPH) and hydroxyl $(\mathrm{OH})$ scavenging assays. The results showed that among the four fractions, the highest $\mathrm{OH}$ radical scavenging activity was exhibited by the $n$-butanol fraction. The DPPH radical scavenging activities of avicularin and isovitexin were higher than $50 \%$ at a concentration of $100 \mu \mathrm{g} / \mathrm{mL}$. Moreover, one hundred micrograms per liter of avicularin and isovitexin exhibited effective anti-oxidant activity, with the $\mathrm{OH}$ radical scavenging rates being 87.54 and $91.48 \%$, respectively. These results suggest that Lespedeza cuneata would be useful anti-oxidant agents from natural sources.
\end{abstract}

Keywords Avicularin · High performance liquid chromatography - Isovitexin - Lespedeza cuneata $\cdot$ Radical scavenging activity

\section{Introduction}

The production of reactive oxygen species during metabolism and the downregulation of anti-oxidant defense systems in the human

Sanghyun Lee $(\bowtie)$

E-mail: slee@cau.ac.kr

${ }^{1}$ Department of Plant Science and Technology, Chung-Ang University, Anseong 17546, Republic of Korea

${ }^{2}$ Department of Food Science, Gyeongnam National University of Science and Technology, Jinju 52725, Republic of Korea

${ }^{3}$ Department of Biology, University of San Carlos, Cebu 6000, Philippines

${ }^{4}$ Department of Food Science and Nutrition, Pusan National University, Busan 46241, Republic of Korea

This is an Open Access article distributed under the terms of the Creative Commons Attribution Non-Commercial License (http://creativecommons. org/licenses/by-nc/3.0/) which permits unrestricted non-commercial use, distribution, and reproduction in any medium, provided the original work is properly cited. body lead to oxidative stress and cellular dysfunction, resulting in chronic disorders such as cancer, cardiovascular diseases, and diabetes, among others [1,2]. Therefore, reducing the oxidative stress is important for the anti-oxidant defense system. Plants have been known to contain natural anti-oxidants, such as flavonoids, which have well-known anti-oxidant properties. Flavonoids are polyphenolic compounds comprised of two benzene rings that are linked together with a heterocyclic pyran or pyrone ring [3]. This particular structure of flavonoids, combined with the position of its hydroxyl groups and the polarity of its glycoside derivatives, contributes to its anti-oxidant properties [4-6]. Flavonoids can also act as modulators of signaling pathways that are directly involved in cellular function and survival, such as the phosphoinositide 3kinase (PI3K), Akt/PKB, and MAPK pathways [7].

Lespedeza cuneata, commonly known as the Chinese bush clover, is a perennial legume native to Asian countries including Korea, Japan, China, and Taiwan. It is used in traditional medicine for the treatment of asthma, chronic cough, abscess, and for eyesight strengthening. In addition, the aerial parts of this plant protect against inflammation, diabetes, and glucose toxicity [810]. Previous studies reported that $L$. cuneata is rich in pinitol, tannins, $\beta$-sitosterol, and flavonoids such as quercetin, kaempferol, and vitexin $[11,12]$. It is also rich in $C$-glycosyl flavones such as desmodin, vicenin II, and isovitexin, and $O$-glycosyl flavonols such as avicularin and trifolin [3]. Among these, avicularin and isovitexin in particular, have various pharmacological activities. Avicularin has hepatoprotective abilities mediated through its radical scavenging properties [13]. It also protects cardiac cells by reducing the release of lactate dehydrogenase from $\mathrm{H} 9 \mathrm{c} 2$ cardiomyocytes exposed to oxidative stress [14]. Isovitexin, on the other hand, possesses effective anti-oxidant, anti-inflammatory, and anti-neoplastic properties [15] and accumulates in the tissues of seedlings exposed to blue light $[16,17]$.

The present study was conducted in an effort to closely investigate the anti-oxidant properties of L. cuneata by analyzing four solvent fractions of the plant. The 2,2-diphenyl-1-picrylhydrazyl (DPPH) and hydroxyl $(\mathrm{OH})$ radical scavenging activities were measured to 
evaluate the anti-oxidant ability of these fractions. The average contents of avicularin and isovitexin in the samples collected from different geographical regions in Korea were simultaneously detected by using high-performance liquid chromatography (HPLC).

\section{Materials and Methods}

Collection of plant materials and preparation of solvent fractions The aerial parts of L. cuneata were collected from Gokseong, Inje, and Boeun, in Korea in the month of October in 2016 and in the month of November in 2017. The voucher specimens were identified by Prof. S. S. Roh, Daegu Haany University and deposited at the herbarium of the Department of Plant Science and Technology, Chung-Ang University, Anseong, Korea. Dried samples of $L$. cuneata were refluxed with methanol (MeOH), and the resulting extract was filtered and evaporated to dryness in vacuo. The extract was solvent partitioned using $n$-hexane, chloroform $\left(\mathrm{CHCl}_{3}\right)$, ethyl acetate (EtOAc), and $n$-butanol (n$\mathrm{BuOH})$.

\section{Chemicals and reagents}

HPLC grade acetonitrile and water were obtained from J. T. Baker (Parkway Center, PA, USA). The 1290 Infinity II LC system with INNO C18 column $(250 \mathrm{~mm} \times 4.6 \mathrm{~mm}, 5 \mu \mathrm{m})$ from Agilent Technology was used for the chemical analyses. The dried aerial portions of $L$. cuneata were extracted three times with $80 \%$ $\mathrm{MeOH}$. The resultant filtrate was evaporated under reduced pressure using a rotavap to obtain the $\mathrm{MeOH}$ extract, which was suspended in distilled $\mathrm{H}_{2} \mathrm{O}$ and successively solvent-partitioned with $n$-hexane, $\mathrm{CHCl}_{3}$, EtOAc, and $n$-BuOH. The compounds from the polar fractions were isolated and identified as avicularin and isovitexin (Fig. 1) [18].

\section{DPPH and $\cdot O H$ radical scavenging activity}

In a 96-well microtiter plate, $100 \mu \mathrm{L}$ of each sample was added to $60 \mu \mathrm{M}$ of an ethanolic solution of DPPH [19]. After mixing with a vortex mixer, the mixture was incubated for $30 \mathrm{~min}$ at room temperature and the absorbance was measured at $540 \mathrm{~nm}$. The DPPH radical scavenging activity was recorded as a percentage in comparison to the control. For the quantification of $\mathrm{OH}$ radical scavenging activity, separate reaction mixtures were prepared, containing $10 \mathrm{mM} \mathrm{FeSO} \cdot 7 \mathrm{H}_{2} \mathrm{O}_{2}$-EDTA, $10 \mathrm{mM}$ 2-deoxyribose, and the sample solutions [20]. After incubation at $37{ }^{\circ} \mathrm{C}$ for $4 \mathrm{~h}$, the reaction was terminated by adding $2.8 \%$ trichloroacetic acid and $1.0 \%$ solution of thiobarbituric acid. The solution was boiled for $20 \mathrm{~min}$ in a water bath and then cooled on ice. The $\mathrm{OH}$ radical scavenging activity was measured at $490 \mathrm{~nm}$.

\section{Preparation of standards and samples for HPLC}

Standard stock solutions of avicularin and isovitexin were separately dissolved in $1 \mathrm{mg} / \mathrm{mL} \mathrm{MeOH}$. The working solutions used to construct the calibration curve were prepared by serially diluting the stock solution to the desired concentrations. Fifteen grams of each sample was extracted with $210 \mathrm{~mL}$ of distilled water for $8 \mathrm{~h}$. All the samples were concentrated in vacuo using an Eyela rotary evaporator. The concentrated samples were then oven-dried for $48 \mathrm{~h}$. The samples were subsequently powderized by freeze-drying. Each of the samples was dissolved in $20 \mathrm{mg} / \mathrm{mL}$ $\mathrm{MeOH}$. Both the standard and the sample solutions were filtered by using a PVDF filter (Cat No. 6779, Piscataway, NJ, USA) having a pore size of $0.45 \mu \mathrm{m}$.

\section{HPLC analytical conditions}

Quantitative analyses of avicularin and isovitexin were performed using a reverse-phase HPLC system and chromatographic separation was achieved using an INNO $\mathrm{C}_{18}$ column $(250 \mathrm{~mm} \times$ $4.6 \mathrm{~mm}, 5 \mu \mathrm{m})$. A gradient elution system, with a mobile phase comprising of $0.5 \%$ acetic acid in water (A) and acetonitrile (B), was utilized. The ratio of the solvents (A:B) in the gradient solvent system was initially 90:10, which was increased in linear gradients to $83: 17$ for $5 \mathrm{~min}$, then to $81: 19$ for $15 \mathrm{~min}$, and finally the mobile phase was maintained for up to $30 \mathrm{~min}$. The temperature of the column was maintained at $35^{\circ} \mathrm{C}$ and the flow rate was set at $1 \mathrm{~mL} / \mathrm{min}$. The injection volume was $10 \mu \mathrm{L}$ and peaks were monitored at $278 \mathrm{~nm}$.

\section{Calibration curve}

Avicularin and isovitexin were dissolved in HPLC grade methanol to prepare solutions having concentrations ranging between 0.25 and $0.015625 \mu \mathrm{g} / \mathrm{g}$. The standards were calculated by using the peak area $(\mathrm{Y})$, concentration $(\mathrm{X}, \mu \mathrm{g} / \mathrm{g})$, and the values of the mean $(\mathrm{n}=5) \pm$ standard deviation (SD). Linear regression was used to determine the linearity of the calibration curve. The contents of

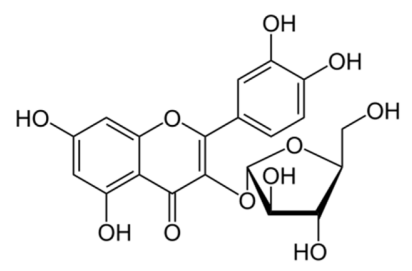

Avicularin

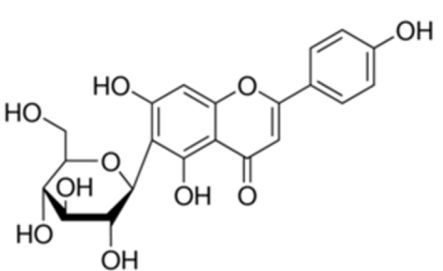

Isovitexin

Fig. 1 Structures of avicularin and isovitexin 
avicularin and isovitexin were determined from the corresponding calibration curves.

\section{Statistical analysis}

Significant differences in the values measured during the experiments were determined using Duncan's Multiple Range Test using the SAS software (version 6.0, SAS Institute, Cary, NC, USA).

\section{Results and Discussion}

The anti-oxidant activities of the solvent fractions of $L$. cuneata and the two compounds, avicularin and isovitexin, were evaluated by using the DPPH and $\mathrm{OH}$ radical scavenging assays. The $\mathrm{OH}$ radical is the most reactive radical and induces oxidative damage in cells [21]. As shown in Table 1, among the four fractions ( $n$ hexane, $\mathrm{CHCl}_{3}, \mathrm{EtOAc}$, and $\left.n-\mathrm{BuOH}\right)$, the $\mathrm{OH}$ radical scavenging activities of the $\mathrm{CHCl}_{3}$ and $n-\mathrm{BuOH}$ fractions were higher than $50 \%$ at a concentration of $250 \mu \mathrm{g} / \mathrm{mL}$. The $n-\mathrm{BuOH}$ fraction (50$250 \mu \mathrm{g} / \mathrm{mL}$ ) had the highest anti-oxidant activity among the four fractions. Our results support the observations of a previous study on the anti-oxidant activity of $L$. cuneata extracts [22] and demonstrate that the EtOAc and $n-\mathrm{BuOH}$ fractions have the highest anti-oxidant activities compared to those of the other fractions [4].

The DPPH radical scavenging activities of avicularin and

Table 1 The hydroxyl radical scavenging activity of the four solvent fractions of L. cuneata

\begin{tabular}{ccccc}
\hline \hline \multirow{2}{*}{$\begin{array}{c}\text { Concentration } \\
(\mu \mathrm{g} / \mathrm{mL})\end{array}$} & $n$-Hexane & $\mathrm{CHCl}_{3}$ & EtOAc & $n$-BuOH \\
\hline 10 & $45.12 \pm 0.28^{\mathrm{b}}$ & $47.59 \pm 1.22^{\mathrm{b}}$ & $40.28 \pm 1.80^{\mathrm{a}}$ & $49.97 \pm 0.05^{\mathrm{c}}$ \\
50 & $49.07 \pm 0.61^{\mathrm{a}}$ & $47.03 \pm 0.83^{\mathrm{b}}$ & $43.37 \pm 0.05^{\mathrm{a}}$ & $53.02 \pm 0.19^{\mathrm{b}}$ \\
100 & $40.55 \pm 1.04^{\mathrm{c}}$ & $44.04 \pm 0.49^{\mathrm{c}}$ & $41.65 \pm 0.58^{\mathrm{a}}$ & $52.21 \pm 0.23^{\mathrm{b}}$ \\
250 & $37.67 \pm 1.24^{\mathrm{c}}$ & $56.26 \pm 0.47^{\mathrm{a}}$ & $41.60 \pm 0.29^{\mathrm{a}}$ & $55.66 \pm 0.43^{\mathrm{a}}$ \\
\hline
\end{tabular}

The values represent the mean percent scavenging activity $\pm \mathrm{SD}$

${ }^{\mathrm{a}-\mathrm{c}}$ The means denoted by different superscript letters differ significantly ( $p$ $<0.05$ ) by Duncan's Multiple Range Test

Table 2 The DPPH scavenging activity of avicularin and isovitexin

\begin{tabular}{ccc}
\hline \hline $\begin{array}{c}\text { Concentration } \\
(\mu \mathrm{g} / \mathrm{mL})\end{array}$ & \multicolumn{2}{c}{ Scavenging activity (\%) } \\
\cline { 2 - 3 } & Avicularin & Isovitexin \\
\hline 100 & $71.28 \pm 0.43$ & $58.20 \pm 3.2$ \\
\hline
\end{tabular}

The values represent the mean percent scavenging activity \pm SD

Table 3 The hydroxyl radical scavenging activity of avicularin and isovitexin

\begin{tabular}{ccc}
\hline \hline \multirow{2}{*}{$\begin{array}{c}\text { Concentration } \\
(\mu \mathrm{g} / \mathrm{mL})\end{array}$} & \multicolumn{2}{c}{ Scavenging activity (\%) } \\
\cline { 2 - 3 } & Avicularin & Isovitexin \\
\hline 100 & $87.54 \pm 0.16$ & $91.48 \pm 0.11$ \\
\hline
\end{tabular}

The values represent the mean percent scavenging activity $\pm \mathrm{SD}$ isovitexin are shown in Table 2. The DPPH radical scavenging effect of avicularin at a concentration of $100 \mu \mathrm{g} / \mathrm{mL}$ was significant, being $71.28 \%$. At a value of $58.20 \%$, the DPPH radical scavenging effect of isovitexin was relatively lower than that of avicularin. However, both avicularin and isovitexin had effective $\mathrm{OH}$ radical scavenging capacities, with values of 87.54 and $91.48 \%$, respectively (Table 3). A number of studies have demonstrated a correlation between the anti-oxidant effect and the structures of flavonoids and phenolic compounds [23,24]. According to Kim and coworkers [13], avicularin, which contains the quercetin aglycone in its structure, exhibits radical scavenging effects, whereas isovitexin, which contains the apigenin aglycone, does not have any 2,2'azino-bis(3-ethylbenzothiazoline-6-sulphonic acid) radical scavenging effects. However, our results indicated that both avicularin and isovitexin have anti-oxidant properties possibly because they can both act as hydrogen donors and/or metal ion chelators [3]. This study further supports this claim and highlights the use of the $n$ $\mathrm{BuOH}$ fraction for future studies on the anti-oxidant properties of

\section{L. cuneata.}

For quantitative analyses, avicularin and isovitexin were simultaneously analyzed. The linear calibration results $\left(r^{2}=\right.$ 0.9999) for both compounds are shown in Table 4 and the quantities of avicularin and isovitexin in L. cuneata are reported in Table 5. The contents of avicularin and isovitexin in the samples of $L$. cuneata collected from the different geographical locations were found to vary (Fig. 2). The contents of avicularin and isovitexin were highest in the samples collected from Gokseong in October 2016, being 0.66 and $1.18 \mathrm{mg} / \mathrm{g}$, respectively. On the other hand, the contents of avicularin and isovitexin were lowest in the samples collected from Inje in November 2016 and from

Table 4 Calibration curves for avicularin and isovitexin

\begin{tabular}{cccc}
\hline \hline Compound & $t_{\mathrm{R}}$ & Calibration equation $^{a}$ & $\begin{array}{c}\text { Correlation factor, } \\
r^{2 b}\end{array}$ \\
\hline Avicularin & 23.7 & $\mathrm{Y}=951.79 \mathrm{X}-0.1937$ & 0.9999 \\
Isovitexin & 17.7 & $\mathrm{Y}=1867 \mathrm{X}+2.7532$ & 0.9999 \\
\hline
\end{tabular}

${ }^{a} \mathrm{Y}=$ peak area, $\mathrm{X}=$ concentration of the standard in $\mathrm{mg} / \mathrm{mL}$

${ }^{b} r^{2}=$ correlation coefficient for three data points in the calibration curve. $t_{R}=$ retention time

Table 5 Contents of avicularin and isovitexin of $L$. cuneata collected from different regions

\begin{tabular}{|c|c|c|c|c|}
\hline \multirow{2}{*}{ Region } & \multirow{2}{*}{ Harvest Time } & \multicolumn{3}{|c|}{ Content (mg/g) } \\
\hline & & Avicularin & Isovitexin & Total \\
\hline \multirow{2}{*}{ Gokseong } & 2016.10 & $0.660 \pm 0.011$ & $1.182 \pm 0.008$ & \multirow{2}{*}{2.214} \\
\hline & 2017.11 & $0.323 \pm 0.042$ & $0.049 \pm 0.012$ & \\
\hline \multirow{2}{*}{ Inje } & 2016.10 & $0.156 \pm 0.047$ & $0.559 \pm 0.044$ & \multirow{2}{*}{1.177} \\
\hline & 2017.11 & $0.128 \pm 0.026$ & $0.334 \pm 0.010$ & \\
\hline \multirow{2}{*}{ Boeun } & 2016.10 & $0.296 \pm 0.021$ & $1.140 \pm 0.027$ & \multirow{2}{*}{1.677} \\
\hline & 2017.11 & - & $0.241 \pm 0.009$ & \\
\hline \multicolumn{2}{|c|}{ Average } & 0.052 & 0.097 & \\
\hline
\end{tabular}

-: not detected 
(A)

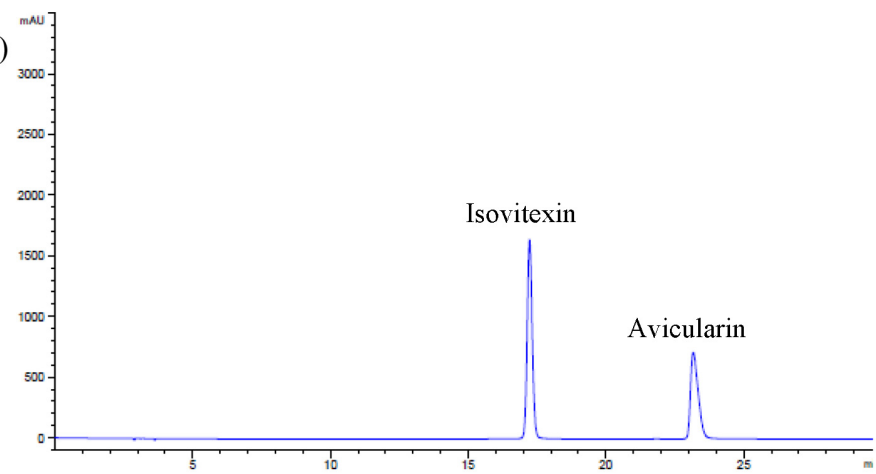

(B)
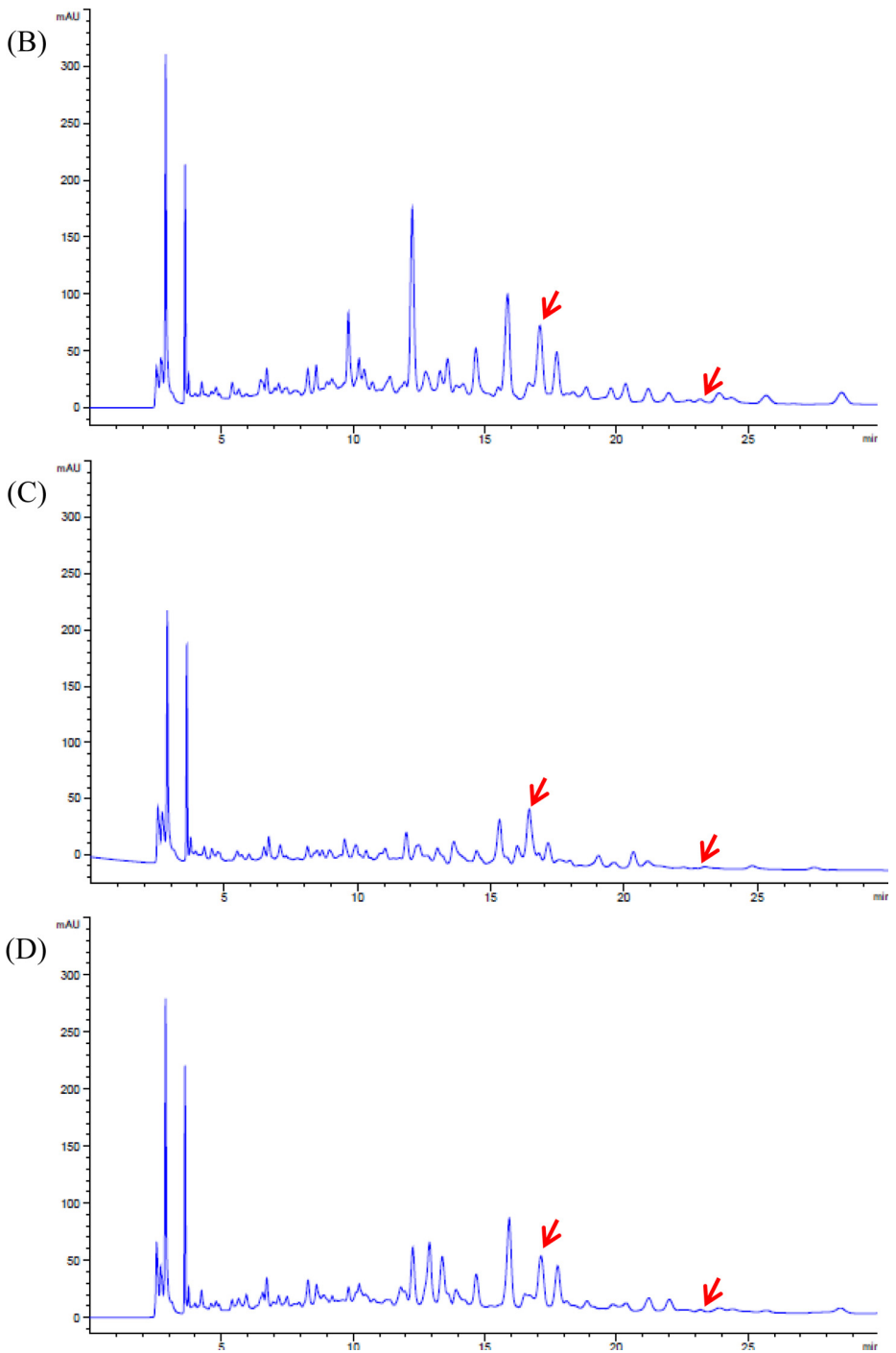

Fig. 2 HPLC chromatograms of the standards (A) and the distilled water extracts of the samples collected from Gokseong (B), Inje (C), and Boeun (D) in 2016

Gokseong in November 2017, respectively. Avicularin was not detected in the samples collected from Boeun in 2017. The difference in the contents could be attributed to seasonal differences, geographic variations, differences in the plant part processed, and the time of harvest. These variations indicated that the use of samples of L. cuneata collected from Gokseong for the isolation of avicularin and isovitexin and other related studies would produce better yields of avicularin and isovitexin if collected the in the month of October than in November. The higher average temperature and monthly total precipitation could 
Table 6 Temperature and precipitation of collection regions

\begin{tabular}{cccc}
\hline \hline Region & Time & $\begin{array}{c}\text { Average } \\
\text { temperature } \\
\left({ }^{\circ} \mathrm{C}\right)\end{array}$ & $\begin{array}{c}\text { Monthly total } \\
\text { precipitation } \\
(\mathrm{mm})\end{array}$ \\
\hline \multirow{2}{*}{ Gokseong } & 2016.10 & 15.5 & 255.0 \\
\hline \multirow{2}{*}{ Inje } & 2017.11 & 5.7 & 4.5 \\
\hline \multirow{2}{*}{ Boeun } & 2016.10 & 13.1 & 107.1 \\
& 2017.11 & 3.8 & 28.2 \\
\hline
\end{tabular}

Source: Korea Meteorological Administration

be attributed the higher content of avicularin and isovitexin (Tables 5 and 6).

Based on our results, the $n-\mathrm{BuOH}$ fraction of $L$. cuneata, which contains higher amounts of flavonoids than the other fractions, exhibited the most effective free radical scavenging activity. The anti-oxidant activity of the $n$-BuOH fraction can be attributed to the compounds avicularin and isovitexin. This study also established that the month of October is a better time for harvesting $L$. cuneata in Gokseong for obtaining maximum yields of avicularin and isovitexin. This study can further improve the development of functional foods with high anti-oxidant effects.

Acknowledgments This research was supported by the funds from the Korean Institute of Planning and Evaluation for Technology in Food Agriculture, Forestry, and Fisheries (iPET) through the Technology Commercialization Support Program funded by the Ministry of Agriculture, Food, and Rural Affairs (MAFRA) (816004-02-1-SB010), Republic of Korea

\section{References}

1. Holliwell B, Gutteridge JM, Cross CE (1992) Free radicals anti-oxidants, and human disease: Where are we now? J Lab Clin Med 119: 598-620

2. Hertog MG, Feskens EJ, Hollman PC, Katan MB, Kromhout D (1993) Dietary anti-oxidant flavonoids and risk of coronary heart disease: the Zutphen elderly study. Lancet 342: 1007-1011

3. Yoo G, Park SJ, Lee TH, Yang H, Baek Y-S, Kim N, Kim YJ, Kim SH (2015) Flavonoids isolated from Lespedeza cuneata G. Don and their inhibitory effects on nitric oxide production in lipopolysaccharidestimulated BV-2 microglia cells. Pharmacogn Mag 11: 651-656

4. Kim HY, Ko JY, Song SB, Kim JI, Seo HI, Lee JS, Kwak DY, Jung TW, Kim KY, Oh IS, Jeong HS, Woo KS (2012) Anti-oxidant and áglucosidase inhibition activities of solvent fractions from methanolic extract of Sericea lespedeza (Lespedeza cuneata G. Don). J Korean Soc Food Sci Nutr 41: 1508-1514

5. Nam J-S, Park S-Y, Jang H-L, Rhee YH (2017) Phenolic compounds in different parts of young Annona muricata cultivated in Korea and their anti-oxidant activity. Appl Biol Chem 60: 535-543

6. Lee J, Rodriguez JP, Lee KH, Park JY, Kang KS, Hahm D-H, Huh CK,
Lee SC, Lee S (2017) Determination of flavonoids from Cirsium japonicum var. maackii and their inhibitory activities against aldose reductase. Appl Biol Chem 60: 487-496

7. Williams RJ, Spencer JP, Rice-Evans C (2014) Flavonoids: anti-oxidants or signalling molecules? Free Radic Biol Med 36: 838-849

8. Choi JS, Cho CS, Kim CJ (2010) Cytoprotective effect of Lespedeza cuneata extract on glucose toxicity. J Korean Oriental Med 31: 79-100

9. Lee H, Jung JY, Hwangbo M, Ku SK, Kim YW, Jee SY (2013) Antiinflammatory effects of Lespedeza cuneata in vivo and in vitro. Kor J Herbol 28: 83-92

10. Kim MS, Sharma BR, Rhyu DY (2016) Beneficial Effect of Lespedeza cuneata (G. Don) water extract on streptozoticin-induced type 1 diabetes and cytokine-induced beta-cell damage. Nat Prod Sci 22: 175-179

11. Kwon DJ, Kim JK, Ham YH, Bae YS (2007) Flavone glycosides from the aerial parts of Lespedeza cuneata G. Don. J Korean Soc Appl Biol Chem 50: 344-347

12. Kwon DJ, Bae YS (2009) Flavonoids from the aerial parts of Lespedeza cuneata. Biochem Syst Ecol 37: 46-48

13. Kim SM, Kang KS, Jho EH, Jung YJ, Nho CW, Um BH, Pan CH (2011) Hepatoprotective effect of flavonoid glycosides from Lespedeza cuneata against oxidative stress induced by tert-butyl hyperoxide. Phytother Res 25: 1011-1017

14. Kim JA, Jung YS, Kim MY, Yang SY, Lee S, Kim YH (2011) Protective effect of components isolated from Lindera erythrocarpa against oxidative stress-induced apoptosis of H9c2 cardiomyocytes. Phytother Res 25: 1612-1617

15. He M, Min J-W, Kong W-L, He X-H, Li J-X, Peng B-W (2016) A review on the pharmacological effects of vitexin and isovitexin. Fitoterapia 115: 74-85

16. Kwon A-R, Oh M-M, Paek K-Y, Park S-Y (2018) The effect of light quality on growth and endopolyploidy occurrence of in vitro-grown Phalaenopsis 'Spring Dancer'. Hort Environ Biotechnol 59: 179-188

17. Nam T-G, Lim YJ, Eom SH (2018) Flavonoid accumulation in common buckwheat (Fagopyrum esculentum) sprout tissues in response to light. Hort Environ Biotechnol 59: 19-27

18. Baek JW, Lee TK, Song J-H, Choi E, Ko H-J, Lee S, Choi SU, Lee S, Yoo S-W, Kim S-H, Kim KH (2018)Lignan glycosides and flavonoid glycosides from the aerial portion of Lespedeza cuneata and their biological evaluations. Molecules 23: 1920-1931

19. Hatano T, Edamatsu R, Hiramatsu M, Mori A, Fujita Y, Yasuhara T, Yoshida T, Okuda T (1989) Effects of the interaction of tannins with coexisting substances, VI. Effects of tannins and related polyphenols on superoxide anion radical and on 1,1-diphenyl-2-pricrylhydrazyl radical. Chem Pharm Bull 37: 2016-2021

20. Chung SK, Osawa T, Kawakishi S (1997) Hydroxyl radical-scavenging effects of spices and scavengers from brown mustard (Brassica nigra). Biosci Biotechnol Biochem 61: 118-123

21. Aruoma OI (1994) Nutrition and health aspects of free radicals and antioxidant. Food Chem Toxicol 62: 671-683

22. Kim JS, Kim MJ (2010) In vitro anti-oxidant activity of Lespedeza cuneata methanolic extracts. J Med Plants Res 2: 674-679

23. Heim KE, Tagliaferro AR, Bobilya DJ (2002) Flavonoid anti-oxidant: chemistry metabolism and structure-activity relationships. J Nutr Biochem 13: 572-584

24. Seyoum A, Asres K, Kandeel Ei-Fiky F (2006) Structure-radical scavenging activity relationships of flavonoids. Phytochemistry 67: 2058-2070 